\title{
Twin entanglement revisited
}

\author{
Richard B Kurzel \\ Department of Obstetrics and Gynecology, University of California, Los Angeles, USA
}

\begin{abstract}
A fear of interlocking twins is one factor that has led to a high Cesarean section (C/S) rate in breech (A)/vertex (B) $\left(\mathrm{Br}_{\mathrm{a}} / \mathrm{Vtx}_{\mathrm{b}}\right)$ twins. We sought to estimate the frequency of occurrence of twin entanglement, and of interlocking $\mathrm{Br}_{\mathrm{a}} / \mathrm{Vtx}_{\mathrm{b}}$ twins in vaginal deliveries. 541 twins and 48195 deliveries were retrospectively studied for the period 1987-1995. The incidence of $\mathrm{Br}_{\mathrm{a}} / \mathrm{Ntx}_{\mathrm{b}}$ deliveries was noted, and the number of deliveries marked by interlocking and collision of fetuses. The mode of delivery, reason for $\mathrm{C} / \mathrm{S}$, and sources of perinatal mortality were noted. Only 43 deliveries were $\mathrm{Br}_{\mathrm{a}} / \mathrm{Vtx} \mathrm{x}_{\mathrm{b}}(7.9 \%$ of all twins) and of these only $14(32.6 \%)$ were delivered vaginally. One case of interlocking (2.3\% of all $\mathrm{Br}_{\mathrm{a}} / \mathrm{Vtx} \mathrm{x}_{\mathrm{b}}$ pairs) and five cases of collision of twins (ie competition for entry into the pelvic inlet with obstruction) were noted. All cases mentioned were delivered by C/S. No perinatal mortality resulted from these cases. In recent years the trend has been for greater use of $\mathrm{C} / \mathrm{S}$ and ultrasound in managing twin deliveries. In this study $67.4 \%$ of $\mathrm{Br}_{\mathrm{a}} \mathrm{Ntx_{ \textrm {b } }}$ twins were delivered by $\mathrm{C} / \mathrm{S}$. Although there are fewer vaginal deliveries of these twins and the rate for interlocking $(2.3 \% ; 95 \% \mathrm{Cl}: 0.06-12.3 \%)$ for the whole group has remained about the same, we found the rate in those twins allowed vaginal delivery was $6.7 \%(95 \% \mathrm{Cl}: 0.2-31.9 \%)$. The presentation at greatest risk for entanglement was found to be $\mathrm{Br}_{a} / \mathrm{Vtx}_{\mathrm{b}}$.
\end{abstract}

Keywords: twin entanglement, twin collision, twin interlocking

\section{Introduction}

Twin entanglement, and interlocking of twins in particular, are such exceedingly rare events that knowledge as to their true incidence and predisposing factors has been derived from compilation of cases reported in the literature..$^{1,2}$ In the absence of multicenter studies, in this work we present what is probably the second largest study of this phenomenon from a single institution, ${ }^{3}$ and on a homogeneous patient population. Interlocking of twins is a complication of vaginal delivery of twins unique for the presentation where the lower twin $(A)$ is in breech presentation, and the more cephal ad twin (B) is in the vertex presentation. Both twins have their chins in direct apposition, which may take place above or below the pelvic inlet. This event has been stated to carry a risk of perinatal mortality as high as $50 \%$, usually for twin $A{ }^{2}$ In many cases, delivery could be accomplished only by decapitation of twin A. Hence the fear of encountering this complication, with its high perinatal mortality, is often suggested to explain the high rate of Cesarean delivery when this presentation is encountered.

In Nissen's original paper, ${ }^{1}$ he classified the four types of twin entanglement as: collision, impaction,

Correspondence: Dr Richard B Kurzel, Department of Obstetrics and Gynecology, Mount Sinai Hospital Medical Center, California Avenue at 15th Street, Room F-208, Chicago, Illinois 60608, USA. Tel: 773257 6727; Fax: 7732576359

Received 23 June 1997; revised 23 July 1998; accepted 8 August 1998 compaction and, least frequently, interlocking. Collision, the most common type of entanglement, involves the contact of fetal parts of both twins with each other, preventing engagement of either. With impaction, there is indentation of any fetal part of one twin on the surface of the second twin, giving partial engagement of both simultaneously. And finally, with compaction one has the simultaneous full engagement of the leading fetal poles of both twins, filling the true pelvis, and preventing further descent or disengagement of either twin.

In this study we examine the mode of delivery for breech-A/vertex-B twins $\left(\mathrm{Br}_{\mathrm{a}} / \mathrm{Vtx}_{\mathrm{b}}\right)$, the stated indications for Cesarean delivery, and the observed incidence of occurrence of interlocking and collision of twins in our population. Lastly, we entertain the question of whether the liberal use of intrapartum ultrasound and Cesarean section has reduced the incidence of this complication.

\section{Materials and methods}

A retrospective study was performed at the Olive View-UCLA Medical Center, a tertiary county hospital, serving the entire northwest quadrant of Los Angeles County. The study spanned a period from 1987-1995. Over this period there were 48195 deliveries, including 541 deliveries of twin gestations. The population studied was largely of Hispanic origin. The presentation of all twins were 
determined intrapartum by ultrasound. The incidence of twin entanglement, and specifically of interlocking of fetuses during delivery, and collision of fetuses was determined from the medical records. The conduct and mode of delivery, the reasons for Cesarean section, and sources of perinatal mortality were noted.

\section{Results}

The distribution of twin pregnancies by presentation of the two fetuses is summarized in Table1. The rather high tendency for twins to be delivered by Cesarean section $(34.6 \%)$ is noted, which is typical for most medical centers in the United States. During this same period, the overall Cesarean section rate at our medical center was $13.1 \%$. Only 43 deliveries were of the presentation $\mathrm{Br}_{\mathrm{a}} / \mathrm{Vtx}_{\mathrm{b}}$, which was only $7.9 \%$ of all twins. Of this group, 27 were allowed to labor, but only $14(32.6 \%)$ were successfully delivered vaginally. The Cesarean section rate for $\mathrm{Br}_{\mathrm{a}} / \mathrm{Vtx}_{\mathrm{b}}$ twins was therefore $67.4 \%$. The indications for these Cesarean sections are given in Table2. A fear of interlocking was specified in the medical records of three patients as the reason for the Cesarean section (which was about 19\% of the elective Cesarean sections, and may have been a factor, although unstated, in 17 other Cesareans done for reason of 'elective Cesarean section', 'failure to progress', 'malpresentation', and 'inadequate pelvimetry'). Interlocking occurred in one patient, which gave an estimated incidence of $2.3 \%(95 \% \mathrm{Cl}=0.06-12.3 \%)$ of all $\mathrm{Br}_{\mathrm{a}} / \mathrm{Vtx}_{\mathrm{b}}$ twins, or $0.2 \%$ of all twins. However, considering the high Cesarean section rate for this presentation, our incidence corrects to $6.7 \%(95 \%$ $\mathrm{Cl}=0.2-31.9 \%)$ of those $\mathrm{Br}_{a} / \mathrm{Vtx}_{\mathrm{b}}$ twins allowed vaginal delivery.

Table 1 Presentation of twins in the study population, as a percentage of that population, and the proportion delivered by Cesarean section

\begin{tabular}{|c|c|c|c|c|c|}
\hline \multicolumn{4}{|l|}{ Presentation } & \multicolumn{2}{|c|}{$\begin{array}{l}\text { Delivered by } \\
\text { Cesarean section }\end{array}$} \\
\hline Twin A & Twin B & No. & $\%$ & No. & $\%$ \\
\hline$\overline{V t x}$ & $\begin{array}{l}\mathrm{Vtx} \\
\mathrm{Br} \\
\text { Transv }\end{array}$ & $\begin{array}{r}231 \\
148 \\
20\end{array}$ & $\begin{array}{r}42.7 \\
27.4 \\
3.7\end{array}$ & $\begin{array}{l}32 \\
33 \\
19\end{array}$ & $\begin{array}{l}13.8 \\
22.3 \\
95.0\end{array}$ \\
\hline $\mathrm{Br}$ & $\begin{array}{l}\text { Vtx } \\
\mathrm{Br} \\
\text { Transv }\end{array}$ & $\begin{array}{l}43 \\
56 \\
17\end{array}$ & $\begin{array}{r}7.9 \\
10.4 \\
3.1\end{array}$ & $\begin{array}{l}29 \\
35 \\
14\end{array}$ & $\begin{array}{l}67.4 \\
62.5 \\
82.3\end{array}$ \\
\hline Transv & $\begin{array}{l}\text { Vtx } \\
\text { Br } \\
\text { Transv }\end{array}$ & $\begin{array}{r}2 \\
7 \\
17\end{array}$ & $\begin{array}{l}0.4 \\
1.3 \\
3.1\end{array}$ & $\begin{array}{r}2 \\
7 \\
16\end{array}$ & $\begin{array}{r}100.0 \\
100.0 \\
94.1\end{array}$ \\
\hline Total & & 541 & 100.0 & 187 & 34.6 \\
\hline
\end{tabular}

The patient with interlocking twins at delivery was a 29-year-old Hispanic female in her fourth pregnancy (para2) who appeared in labor at 37 weeks' gestation. Presentation was determined by ultrasound on labor and delivery. Twin A was in a complete breech presentation. Arrest of descent of twin A was noted, with twin A delivered between the fetal iliac crest and the scapula. Fetal tachycardia and severe variable decelerations were noted on electronic fetal monitoring. Late decelerations were noted on the tracing of twin $\mathrm{B}$, later determined to be secondary to placental abruption. Ultrasound confirmed direct chin apposition. The babies were delivered by emergency primary Cesarean section. The upper twin was dislodged cephalad and laterally intraoperatively to allow delivery of this twin first. The lower twin was female, weighing $2840 \mathrm{gm}$ (Apgars $7 / 8$ ), whilst the upper twin was male weighing 3910 gm (Apgars 4/7/9).

In addition, five cases of collision were noted, that is competition for entry into the pelvic inlet, with obstruction. All cases of collision were noted for twins whose axis was parallel to each other, and to the maternal axis. In four cases, the lower twin was breech, and the upper twin vertex. In one case, both were in the breech presentation. No Vtx/Vtx collisions were seen in this series, nor were any entanglements seen where the axes of the twins were not parallel. Although it is difficult to delineate cases of collision from simple dystocia, in all five cases no descending part entered the pelvis, and ultrasound confirmed that two fetuses with parallel axes were attempting entry into the pelvic inlet at the same time. The incidence of entanglement in the total population of twins was $1.1 \%(95 \% \mathrm{Cl}=0.4-2.4 \%)$, and $2.4 \%(95 \% \mathrm{Cl}=0.9-5.2 \%)$ in twins where their axes were parallel ( $\mathrm{Vtx} / \mathrm{Br}, \mathrm{Br} / \mathrm{Vtx}, \mathrm{Br} / \mathrm{Br})$. The incidence for collision alone was $0.9 \% \quad(95 \%$ $\mathrm{Cl}=0.3-2.1 \%)$ of the total population of twins, and $2.0 \%(95 \% \mathrm{Cl}=0.7-9.7 \%)$ of twins whose axes were

Table 2 Stated indications for Cesarean section in $\mathrm{Br}_{2} / \mathrm{Vtx}_{\mathrm{b}}$ twins ${ }^{a}$

\begin{tabular}{lr}
\hline Elective Cesarean sections & No. \\
\hline Not in labor: & 1 \\
repeat Cesarean & 3 \\
double footling breech (A) & 3 \\
concern of interlocking & 1 \\
fear of cord entangl ement & \\
inadequate pelvimetry & 3 \\
no reason given & 5 \\
Complications of Labor: & 2 \\
cord prol apse (A) & 5 \\
'failure to progress' & 1 \\
abruption & 4 \\
collision & 1 \\
interlocking & 29 \\
Total &
\end{tabular}

${ }^{a}$ no Cesarean sections were done for twin-B al one;

${ }^{b}$ monoamniotic-monochorionic twins diagnosed by ultrasound. 
Table 3 Entanglement in twins

\begin{tabular}{|c|c|c|c|c|c|}
\hline & maternal age (yrs) & parity & gestational age (wks) & presentation & birth weight (gm) \\
\hline \multicolumn{6}{|l|}{ Collision } \\
\hline pair 1 & 35 & 0 & $375 / 7$ & $\begin{array}{l}\operatorname{Br}(A) \\
\operatorname{Vtx}(B)\end{array}$ & $\begin{array}{l}2895 \mathrm{~F} \\
2825 \mathrm{M}\end{array}$ \\
\hline pair 2 & 21 & 0 & $355 / 7$ & $\begin{array}{l}\operatorname{Br}(A) \\
\operatorname{Vtx}(B)\end{array}$ & $\begin{array}{l}2685 \mathrm{~F} \\
2725 \mathrm{~F}\end{array}$ \\
\hline pair 3 & 37 & 5 & 27 & $\begin{array}{l}\operatorname{Br}(A) \\
\operatorname{Br}(B)\end{array}$ & $\begin{array}{l}1375 \mathrm{M} \\
1115 \mathrm{M}\end{array}$ \\
\hline pair 4 & 23 & 1 & $403 / 7$ & $\begin{array}{l}\operatorname{Br}(A) \\
\operatorname{Vtx}(B)\end{array}$ & $\begin{array}{l}3135 \mathrm{M} \\
2730 \mathrm{~F}\end{array}$ \\
\hline pair 5 & 25 & 1 & $305 / 7$ & $\begin{array}{l}\operatorname{Br}(A) \\
\operatorname{Vtx}(B)\end{array}$ & $\begin{array}{l}1475 \mathrm{M} \\
1555 \mathrm{M}\end{array}$ \\
\hline $\begin{array}{l}\text { Interlocking } \\
\text { pair } 6\end{array}$ & 29 & 2 & $373 / 7$ & $\begin{array}{l}\operatorname{Br}(A) \\
\operatorname{Vtx}(B)\end{array}$ & $\begin{array}{l}2840 \mathrm{~F} \\
3910 \mathrm{M}\end{array}$ \\
\hline mean & $28.3 \pm 6.0$ & $1.5 \pm 1.5$ & $34.8 \pm 4.6$ & & $2439 \pm 816$ \\
\hline
\end{tabular}

parallel. Information describing each of the entangled pairs is given in Table 3. In only two cases was the type of breech presentation specified in the entanglements. In pair No.5 the presentation was one of double footling breech, whilst in pair No.6 (the interlocking pair), one had a complete breech presentation.

No perinatal mortality resulted from any of these six cases.

\section{Discussion}

Because interlocking of twins is a rare event, few series studying this phenomenon are large enough accurately to estimate its frequency of occurrence, or determine the predisposing factors. The rarity of this event is partly due to the requirement for the presentation to be $\mathrm{Br}_{\mathrm{a}} / \mathrm{Vtx} \mathrm{x}_{\mathrm{b}}$. Previous studies have shown 'twin A non-vertex/B other' to be the least common intrapartum twin presentation, with incidence ranging from $12.6^{4}$ to $29.9 \% .^{5}$ In our series it was found to be $26.2 \%$, with $\mathrm{Br}_{\mathrm{a}} / \mathrm{Vtx}_{\mathrm{b}}$ specifically being $7.9 \%$ of our population of twins. Other uncertain factors account for the two chins aligning in direct apposition for interlocking to occur.

Interlocking is the least common type of entanglement, although the most lethal. In this series, six cases of entanglement were noted, with the majority $(83 \%)$ being in collision, in agreement with the findings of Nissen. ${ }^{1}$ Only one of these entangled pairs was interlocked, a relative proportion also noted by Nissen. We confirm his finding that the presentation at greatest risk for entanglement is $\mathrm{Br}_{a} /$ $\mathrm{Vtx}_{\mathrm{b}}$, as was noted in one of six of our cases.

Our estimated incidence for interlocking of $\mathrm{Br}_{\mathrm{a}} \mathrm{l}$ $\mathrm{Vtx}_{\mathrm{b}}$ twins was roughly similar to that found in Sweden, ${ }^{6} 1 / 91$, and that quoted by Cohen ${ }^{2}$ from the Obstetrical Statistical Cooperative, 1/87.7. However, when looking only at $\mathrm{Br}_{\mathrm{a}} / \mathrm{Vtx}_{\mathrm{b}}$ twins who were allowed vaginal delivery, our incidence of $2.3 \%$
$(95 \% \mathrm{Cl}=0.06-12.3 \%)$ of all $\mathrm{Br}_{a} / \mathrm{Vtx}_{\mathrm{b}}$ twins corrects to $6.7 \%(95 \% \mathrm{Cl}=0.2-31.9 \%)$. Keith ${ }^{7}$ noted a trend in Sweden where this rate was observed to fall from $1 / 74(1961-66)$ to $1 / 189$ (1981-87). It was suggested that this was due to an increased use of ultrasound and Cesarean section in recent years. Although the numbers are small, in spite of a liberal use of intrapartum ultrasound and Cesarean section in our series, this trend was not seen. It is reasonable to expect, however, that with the diligent use of ultrasound during the second stage of labor, all pregnancies complicated by entanglement could be identified, allowing intervention with Cesarean section.

A number of suggestions have been proposed to aid in the management of the delivery once interlocking or entanglement presents itself. Cohen ${ }^{2}$ has proposed doing a frontal and lateral X-ray on all twins of parallel lie with opposite poles, to ascertain if the limbs of twin B and head of twin $A$ have entered the pelvic inlet. Downward traction of twin $A$ is to be avoided, while one dislodges and displaces laterally the head of twin B. This dislodging of the heads may be aided by the use of betasympathomimetic agents, as suggested by Sevitz, ${ }^{8}$ or by the use of general anesthesia. Simultaneous delivery of both heads has been described (KimballRand Maneuver), hyperextending head A, while flexing head B using Piper forceps. ${ }^{1}$ In some cases, none of these maneuvers are successful, necessitating decapitation of twin $A$ in order to salvage twin B.

Rydhström and Cullberg ${ }^{6}$ noted predisposing factors for interlocking to be the presence of intrauterine growth retardation, birth weight under $2000 \mathrm{gm}$, and antenatal death of twin A. In addition, Nissen ${ }^{1}$ and Cohen $^{2}$ noted the association to be highest in young (under age 30 ) primigravidas, when there was rupture of the membranes or oligohydramnios in the second sac, or small babies in a large pelvis. Although all these factors appear reasonable, 
and should be recognized as risk factors for interlocking, our one case of interlocking did not satisfy most of these criteria, and in fact is remarkable for the large size of these babies.

In summary, twins in the $\mathrm{Br}_{\mathrm{a}} / \mathrm{Vtx}_{\mathrm{b}}$ presentation have the highest risk for twin entanglement. Most of these cases result in fetal collision with obstruction, and may be predicted by intrapartum ultrasound. These deliveries are by Cesarean section with good maternal and fetal outcomes. In $20 \%$ of the cases of $\mathrm{Br}_{\mathrm{a}} / \mathrm{Vtx}_{\mathrm{b}}$ entanglements, however, interlocking may occur, with about $50 \%$ risk of fetal loss. Since these entanglements are a complication of the late second stage of labor, they are not easily predicted, and hence even the American College of Obstetricians and Gynecologists ${ }^{4}$ considers an abdominal delivery the preferred mode for this presentation.

\section{References}

1 Nissen ED. Twins: collision, impaction, compaction, and interlocking. Obstet Gynecol 1958; 11: 514-526.

2 Cohen M, Kohl SG, Rosenthal AH. Fetal interlocking complicating twin gestation. Am J Obstet Gynecol 1965; 91: 407-412.

3 Blickstein I. Vaginal delivery of breech-vertex twins. J Reprod Med 1993; 38: 879-882.

4 Gall SA. Multiple Pregnancy and Delivery. Mosby Co: St Louis, MO, 1996, p 267.

5 Divon MY. Twin gestations: Fetal presentation as a function of gestational age. Am J Obstet Gynecol 1993; 168: 1500-1502.

6 Rydhström H, Cullberg G. Pregnancies with growth retarded twins in breech-vertex presentation at increased risk for entanglement during delivery. J Perinat Med 1990; 18: 45-50.

7 Keith LG, Papiernick E, Keith DM, Luke B. Multiple Pregnancy: Epidemiology, Gestation, and Perinatal Outcomes. Parthenon Publ. Co: New York, 1995, pp 211-212.

8 Sevitz H, Merrell DA. The use of beta-sympathomimetic drug in locked twins. Br J Obstet Gynecol 1981; 88: 76-77. 